\title{
ADAMTS13 activity decreases in the early phase of trauma associated with coagulopathy and systemic inflammation: a prospective observational study
}

Hironori Matsumoto*, Jun Takeba, Kensuke Umakoshi, Satoshi Kikuchi, Muneaki Ohshita, Suguru Annen, Naoki Moriyama, Yuki Nakabayashi, Norio Sato and Mayuki Aibiki

\begin{abstract}
Background: We conducted a prospective observational study for investigating the changes in the 13th member of a disintegrin-like and metalloprotease with thrombospondin type 1 motif (ADAMTS13) and its association with the coagulofibrinolytic response in adult trauma patients.

Methods: In 39 trauma patients hospitalized for longer than 7 days, time-course changes in biomarkers of coagulofibrinolysis and systemic inflammation along with ADAMTS13 activity were examined. The patients were stratified into three groups based on ADAMTS13 activities on admission (day 0): normal group ( $\geq 70 \%$ ), mildly decreased group ( $\geq 50$ and $<70 \%$ ) and moderately decreased group $(<50 \%)$.

Results: Among 39 patients with a median Injury Severity Score (ISS) of 20, 11 patients developed disseminated intravascular coagulation (DIC) and 16 patients required transfusion. Six of 39 patients (15.4\%) showed moderate decreased ADAMTS13 activity to $<50 \%$, and 20 patients (51.3\%) showed mild drops ( $\geq 50$ and $<70 \%$ ). These changes in ADAMTS13 activity on day 0 were significantly correlated with changes in IL-6 and other coagulofibrinolytic markers such as platelet counts, prothrombin time and fibrin/fibrinogen degradation product (FDP). Antithrombin activity (AT) and serum albumin (Alb) level showed significantly positive linear correlations with ADAMTS13 activity (AT: $r=0.513, p<0.001$; Alb: $r=0.647, p<0.001$ ). Simple logistic regression analyses showed that ADAMTS13 activity, if less than 50\%, was significantly correlated with the development of DIC $(O R 7.499,95 \% \mathrm{Cl}$ $1.121-49.242, p=0.038)$ and the need for transfusion of fresh frozen plasma (OR 9.000, 95\%Cl 1.327-61.025, $p=$ 0.028).

Conclusions: ADAMTS13 activity decreased even in the early phase of trauma, which was complicated by coagulopathy and systemic inflammation. Furthermore, the decrease in ADAMTS13 activity was correlated with DIC and plasma transfusion.
\end{abstract}

Keywords: Albumin, Antithrombin, Coagulofibrinolysis, Disseminated intravascular coagulation (DIC), Extravascular leakage

\footnotetext{
* Correspondence: matsumotohiro0611@yahoo.co.jp

Department of Emergency and Critical Care Medicine, Ehime University, Graduate School of Medicine, Shitsukawa 454, Toon City, Ehime 791-0295, Japan
}

C C The Author(s). 2021 Open Access This article is licensed under a Creative Commons Attribution 4.0 International License, which permits use, sharing, adaptation, distribution and reproduction in any medium or format, as long as you give appropriate credit to the original author(s) and the source, provide a link to the Creative Commons licence, and indicate if changes were made. The images or other third party material in this article are included in the article's Creative Commons licence, unless indicated otherwise in a credit line to the material. If material is not included in the article's Creative Commons licence and your intended use is not permitted by statutory regulation or exceeds the permitted use, you will need to obtain permission directly from the copyright holder. To view a copy of this licence, visit http://creativecommons.org/licenses/by/4.0/. The Creative Commons Public Domain Dedication waiver (http://creativecommons.org/publicdomain/zero/1.0/) applies to the data made available in this article, unless otherwise stated in a credit line to the data. 


\section{Background}

The 13th member of a disintegrin-like and metalloprotease with thrombospondin type 1 motif (ADAMTS13) is secreted from hepatic stellate and endothelial cells, and reduces von Willebrand factor (vWF) coagulation activities by cleaving vWF multimers into small fragments, and thus plays an important role in regulating thrombosis. vWF is mainly synthesized from endothelial cells and megakaryocytes, and is then stored in WeibelPalada bodies and platelet $\alpha$ granules. The bioactivity of vWF's coagulation function depends on its molecular weight; its higher molecular type exhibits more powerful activities. The monomer of vWF is $250 \mathrm{kDa}$, and vWFs present in plasma with molecular weight of 500-15,000 $\mathrm{kDa}$. vWF multimers in the storage granules of endothelial cells are rich in a highly thrombogenic form of unusually large vWF multimers (ULvWF). If endothelial cells were injured, ULvWF will be released from the granules into the blood, and facilitates platelet adhesion and aggregation, then cleaved by ADAMTS13 as stated above. Therefore, deficiency of ADAMTS13 could cause the formation of microvascular thrombosis [1-6]. Thrombotic microangiopathy (TMA) is a pathological diagnosis established by the presence of thrombosis in small vessels and involves thrombotic thrombocytopenic purpura (TTP) and hemolytic uremic syndrome (HUS) $[4,7]$. Severe ADAMTS13 deficiency such as hereditary or acquired TTP provokes life-threatening thrombotic sequelae. On the other hand, some acute critical diseases such as sepsis are often complicated by a secondary mild to moderate decrease in ADAMTS13 levels, which is thought to be one of the heterogenic reactions, even without the development of TMA or TTP $[4,8]$. Secondary ADAMTS13 deficiency is considered to develop as a result of endothelial cell injury [9], and also this deficiency is known to be well associated with thrombotic disorders and severity or prognosis of primary diseases. Regarding trauma, in a pediatric study, ADAMTS13 decreased with vWF elevation, which was associated with coagulopathy and endothelial cell injury [10]. Nevertheless, the changes in ADAMTS13 levels in a trauma setting have not been sufficiently elucidated. The aim of this study is to examine the changes in ADAMTS13 activity and to evaluate its association with coagulofibrinolysis and inflammation in adult trauma patients.

\section{Methods}

\section{Study design}

We performed a prospective observational study by collecting the data of adult trauma patients admitted to the tertiary Ehime University Hospital in Japan from January 2015 to April 2016. This study was approved by the Institutional Local Ethics Committee for Clinical Studies.
Informed consent was obtained from all patients or next of kin in accordance with the Declaration of Helsinki.

\section{Patient selection and criteria}

All adult trauma patients ( $\geq 18$ years) who were immediately admitted to our hospital, or were transferred from other hospitals without any significant therapeutic interventions, and were estimated to require hospitalization for more than 7 days were enrolled. We excluded patients who had already received therapeutic interventions including infusion (more than $500 \mathrm{~mL}$ of fluid administration or medications before transfer to our hospital), those who had died during initial treatments at the emergency department, those who had an episode of cardiac arrest, those who received anticoagulant therapy, and those who had a clotting disorder such as liver cirrhosis or advanced malignancies.

Demographic data, examinations, treatments, and mortality were recorded. Trauma usually causes dynamic coagulofibrinolytic changes. Excessive thrombin generation and remarkably enhanced fibrinolysis beyond the physiological response lead to a pathophysiological condition such as trauma-induced coagulopathy (TIC) and disseminated intravascular coagulation (DIC) [11]. The pathological coagulopathy would be clearly distinguished from the physiological hemostasis especially when DIC diagnosis criteria were used [12]. We therefore used DIC criteria for the assessment of the patients who developed pathological coagulopathy. Systemic inflammatory response syndrome (SIRS) was defined according to the consensus conference of the American College of Chest Physicians/Society of Critical Care Medicine [13]. The diagnosis for DIC was made based on the Japanese Association for Acute Medicine (JAAM) DIC criteria [14], according to which, patients with a score of at least 4 were diagnosed with DIC. Deep venous thrombosis was diagnosed by ultrasonography on day 6 . The decision and timing for initiating pharmacological VTE prophylaxis were at the discretion of the physicians in charge after the evaluation of the patients' condition. Transfusions of packed red blood cells, fresh-frozen plasma, or platelets were allowed in order to maintain the hemodynamics and the hemostasis at the discretion of the clinicians informed by the laboratory data.

The normal ADAMTS13 activity is $100 \%$, ranging from 70 to $120 \%$. Thus, we stratified the patients into three groups according to the ADAMTS13 activities on arrival (day 0): normal ( $\geq 70 \%$ ); slightly decreased, showing less than the lower normal limit ( $\geq 50$ and $<70 \%)$; and moderately decreased, showing less than half the normal activity $(<50 \%)$.

\section{Blood sampling and measurement}

Blood sampling was performed immediately upon arrival (day 0 ) and on days $1,2,4$, and 6 . We routinely measured blood counts and biochemistries including 
albumin (Alb), and C-reactive protein (CRP) with TBA-c16000 (Toshiba Medical Systems, Tochigi, Japan) and XE-5000 (Sysmex, Hyogo, Japan). We also measured the biomarkers of coagulofibrinolysis using CP-2000 (Sekisui Medical, Tokyo, Japan) and STACIA (LSI Medience, Tokyo, Japan): prothrombin time (PT), activated partial thromboplastin time (APTT), hepaplastin test (HPT), fibrinogen (Fbg), fibrin/fibrinogen degradation product (FDP), D-dimer, soluble fibrin (SF), thrombin-antithrombin complex (TAT), plasmin- $\alpha_{2}$-plasmin inhibitor complex (PIC), antithrombin (AT), protein $\mathrm{C}(\mathrm{PC}), \alpha_{2}$-plasmin inhibitor $\left(\alpha_{2} \mathrm{PI}\right)$, and plasminogen (PLG). After sampling, the blood samples were centrifuged at $3300 \mathrm{rpm}$ for 15 min at $4{ }^{\circ} \mathrm{C}$, and serum and plasma samples were stored at $-80^{\circ} \mathrm{C}$ for subsequent analyses. We measured total plasminogen activator inhibitor-1 (tPAI-1) on days $0,1,2$ and 6; soluble thrombomodulin (sTM) and ADAMTS13 activity on days 0, 2 and 6; and IL-6 on day 0. tPAI-1 represents the sum of active PAI-1, t-PA/PAI-1 and latent PAI-1, and was measured by the LPIA.tPAI-1 test with the automated immunoanalyzer STACIA (LSI Medience Corporation, Tokyo, Japan). sTM was measured by one-step sandwich enzyme immunoassay using a monoclonal antibody specific for thrombomodulin (TM Panacella; Fujirebio, Tokyo, Japan). ADAMTS13 activity was measured by enzyme immunoassay (ADAMTS13 Activity ELISA Kit; KAINOS Laboratories, Inc., Tokyo, Japan) [15]. IL-6 was measured by enzyme-linked immunosorbent assay (Human IL-6 Quantikine ELISA kit, R\&D Systems, Minneapolis, MN, USA).

\section{Statistical analysis}

Statistical analyses were performed using IBM SPSS statistics 22 (IBM, Tokyo, Japan). All data are expressed as median (interquartile range: IQR). A comparison between two of the groups was performed using the Mann-Whitney $U$ test, and a comparison among all three groups was performed using the Kruskal-Wallis test. Time course changes of ADAM TS13 activity during the study period were tested by one-way repeated measures analysis of variance (ANOVA). The longitudinal differences in ADAM TS13 activities during the study period between the subgroups stratified with the activities on day 0 were analyzed by two-way repeated measures ANOVA. The relationships between the dependent variables were analyzed with a linear regression analysis. A stratified logistic regression analysis was used to generate odds ratios (ORs) and confidence intervals (CIs) for categorical valuables. A $p$ value less than 0.05 was considered significant.

\section{Results}

Characteristics of patients enrolled (Table 1)

Fifty-nine trauma patients were admitted to our hospital during the study period. Twenty patients were excluded based on the exclusion criteria, as stated in the Methods section. As a result, this study included 39 adult trauma patients with a median Injury Severity Score (ISS) of 20 (10-27). The baseline characteristics and coagulofibrinolytic parameters on day 0 are presented in Table 1 . The traumatic mechanism for all the patients was blunt injury, so most of them suffered several organ injuries. During the study period, 17 of the patients (43.5\%) underwent transfusion, 16 of who $(94.1 \%)$ received a transfusion on day 0 . Therapies such as interventional radiology (IVR), craniotomy, laparotomy, or open reduction and internal fixation (ORIF) were performed on 21 patients (53.8\%), ten of who (47.6\%) underwent these interventions on day 0 . Twenty patients $(51.3 \%)$ received pharmacological VTE prophylaxis during the course. The development of DVT without related symptoms was observed in six patients (15.3\%).

The parameters reflecting the systemic inflammatory response and coagulofibrinolytic activation notably increased on day 0 (IL-6, 108.5 [40.8-250.3] pg/mL; TAT, 88.0 [30.1-200.0] $\mu \mathrm{g} / \mathrm{L} ; \mathrm{PIC}, 9.1$ [2.8-17.8] $\mu \mathrm{g} / \mathrm{mL}$; FDP, $63.0[31.4-168.1] \mu \mathrm{g} / \mathrm{mL}$ ). Eleven patients met the JAAM DIC criteria and 17 patients required transfusion. Two patients $(5.1 \%)$ died from brain swelling due to severe head injury after the 7-day study period.

\section{ADAMTS13 activity on day 0 and its changes during the study period (Table 1 and Fig. 1)}

The median ADAMTS13 activity of all the patients on day 0 was $63.6(56.4-74.5) \%$. Six of 39 patients (15.4\%) showed moderately decreased ADAMTS13 activity (< $50 \%)$, and 20 patients $(51.3 \%)$ showed a slight depletion $(\geq 50$ and $<70 \%$ ). The median values of the moderately decreased group, the slightly decreased group, and the normal group were $44.6(42.1-47.7) \%, 61.2$ (56.5$63.0) \%$, and $76.7(75.5-82.5) \%$, respectively $(p<0.001)$ (Table 1). However, the differences in ADAMTS13 activities among the three groups disappeared following the study period ( $p=0.84$ ) (Fig. 1).

\section{Correlation between ADAMTS13 activities and the coagulofibrinolysis related parameters on day 0 (Figs. 2 and 3 and Tables 1 and 2)}

ADAMTS13 activities on day 0 were significantly correlated with IL- 6 values at the same point $(p=0.037)$, but not with ISS or Lactate $(p=0.75, p=0.43)$ (Table 1$)$. The coagulofibrinolytic markers including PLT, PT, HPT, FDP, D-dimer, PIC, AT, PC, $\alpha_{2}$ PI and Alb were also correlated with ADAMTS13 activities on day $0(p<$ 0.05) (Table 1, Fig.2). Though insignificant, there was 
Table 1 Patients clinical features and outcomes

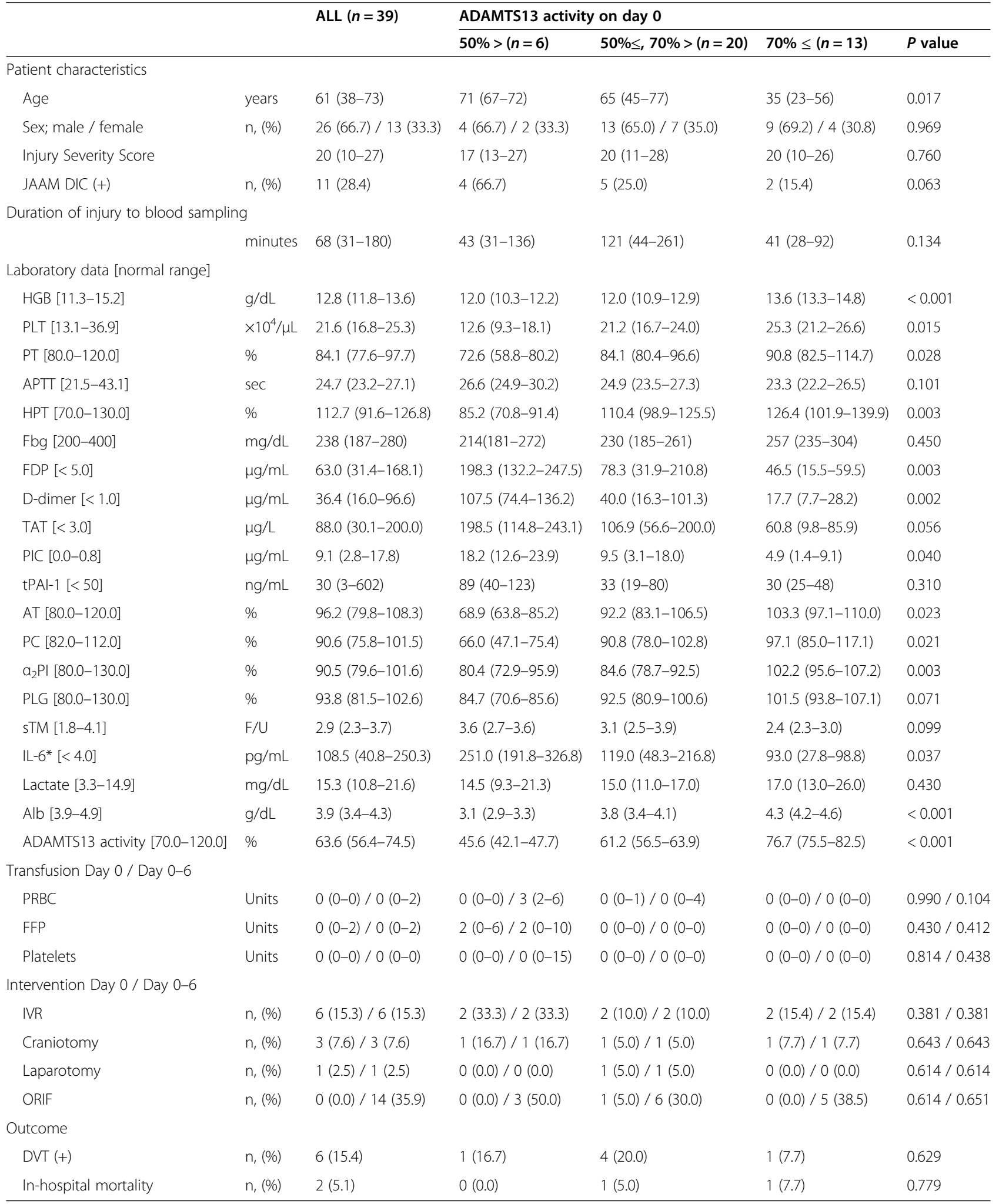

Values are presented as median (interquartile range: IQR) or number (\%), if appropriate

*Measurements of 38 patients. We started to measure IL-6 from the second patient of this study 


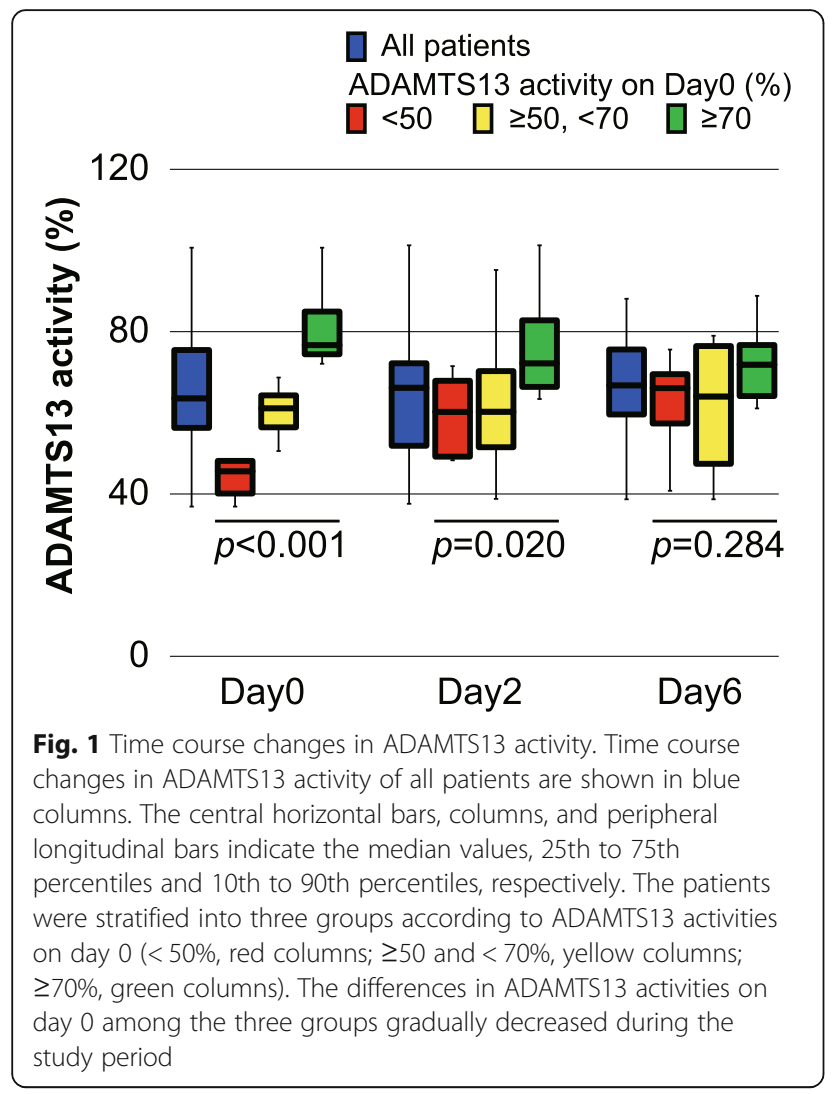

also a trend of correlations between ADAMTS13 activities and the values of other coagulofibrinolytic parameters (Table 1). Serum Alb levels and plasma AT activities showed significant linear correlations with ADAMTS13 activities (Alb: $r=0.647, p<0.001$; AT: $r=0.513, p<$ 0.001 ), which were accompanied by significant

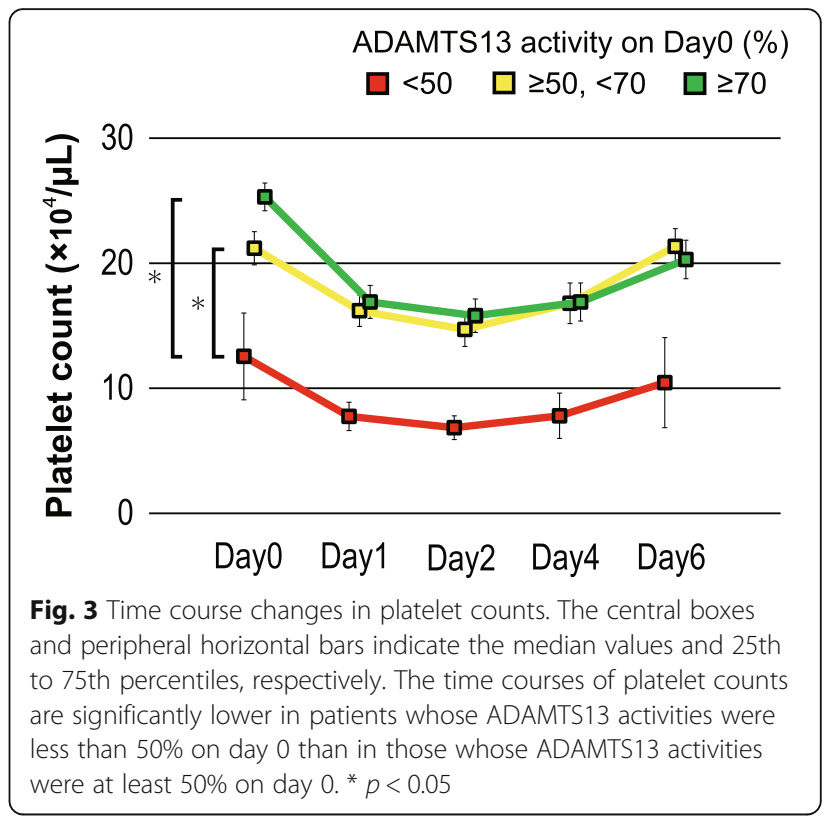

correlations of platelet counts and D-dimer levels with ADAMTS13 activities (PLT: $r=0.428, p=0.007$; Ddimer: $r=0.436, p=0.005$ ) (Fig. 2).

The moderately decreased ADAMTS13 activities to less than $50 \%$ on day 0 were significantly associated with the consumption of platelets (Fig. 3). Simple logistic regression analyses showed that ADAMTS13 activity when decreased to the levels less than $50 \%$ was significantly correlated with the development of DIC (OR 7.429, 95\%CI 1.121-49.244, $p=0.038$ ) and the need for transfusion of fresh frozen plasma (FFP) (OR 9.000, 95\%CI 1.327-61.025, $p=0.028$ ) (Table 2). However, the
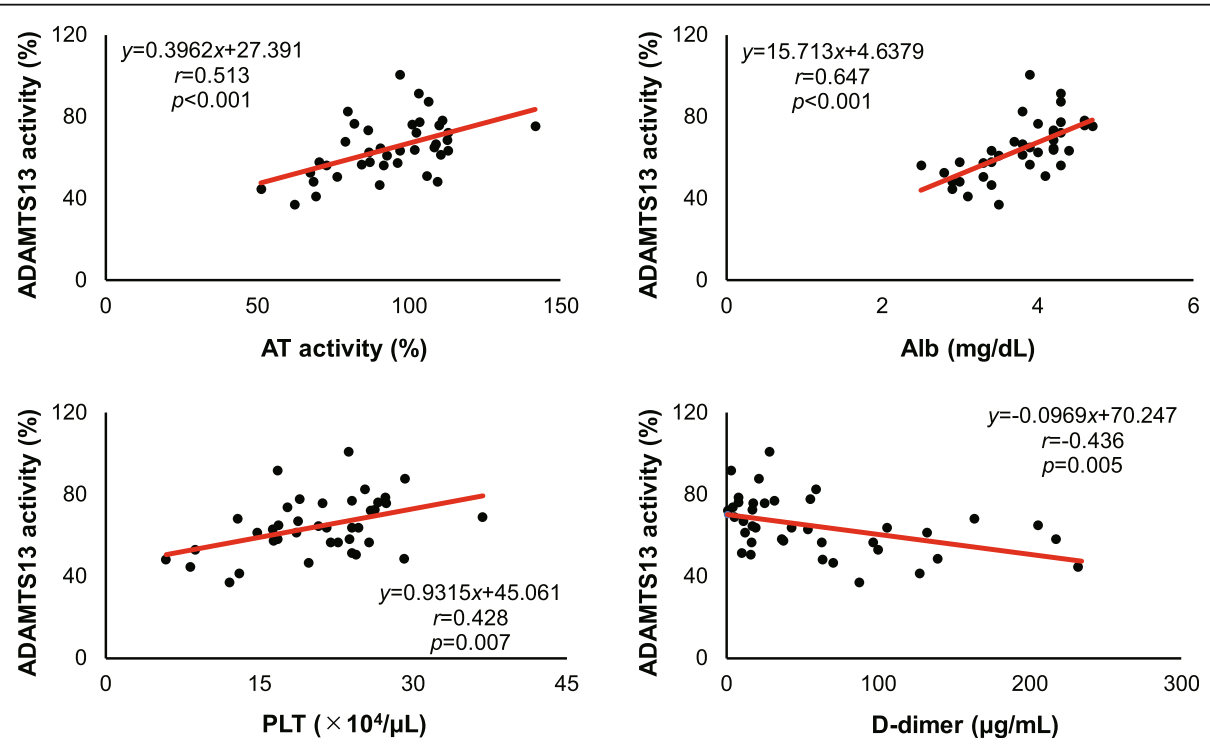

Fig. 2 Single linear regression analyses of ADAMTS13 activities with AT activities (upper left), serum Alb levels (upper right), platelet counts (lower right), and D-dimer levels (lower left) on day $0 . r$, correlation coefficient; $p, p$ value 
Table 2 Simple logistic analyses for outcomes and treatments associated with the decreased ADAMTS13 activity to less than $50 \%$ on day $0(n=39)$

\begin{tabular}{lll}
\hline & OR $(\mathbf{9 5 \%}$ Cl) & P value \\
\hline Development of DVT & $1.120(0.107,11.726)$ & 0.925 \\
Development of DIC & $7.429(1.121,49.244)$ & 0.038 \\
Requirement of transfusion of FFP & $9.000(1.327,61.025)$ & 0.028 \\
\hline OR odds ratio, Cl confidence interval & &
\end{tabular}

decreased ADAMTS13 activity was not correlated with the development of DVT (OR 1.120, 95\% CI 0.10711.726, $p=0.925$ ) (Table 2).

\section{Discussion}

Plasma levels of ADAMTS13 activity in trauma patients Suppressed ADAMTS13 activity less than $10 \%[4,7,8]$ is a cause of TTP, showing remarkable platelet consumption leading to thrombotic microangiopathy (TMA). Alternatively, there are slightly or moderately decreased ADAMTS13 activities with secondary thrombotic disorders such as sepsis [16-20] or other conditions [21-23]. However, ADAMTS13 has not been evaluated in adult trauma patients. Recently, in pediatric trauma patients, Russel et al. reported slightly decreased ADAMTS13 activities from 74.3 to $83.0 \%$ during the first $24 \mathrm{~h} \mathrm{[10].} \mathrm{In} \mathrm{the} \mathrm{current} \mathrm{study} \mathrm{of} \mathrm{adult} \mathrm{trauma} \mathrm{pa-}$ tients, the median ADAMTS13 activity on day 0, which means the condition of just starting the initial treatments in the emergency room as shown in the method section, was $63.6 \%$. Approximately $66.7 \%$ of the patients showed decreased ADAMTS13 activity below the lower limit of the normal range of $70 \%$. Furthermore, a reduction to less than $50 \%$ was observed in $15.4 \%$ of all the patients. These results indicate that ADAMTS13 activity could decrease even in the early phase of adult trauma patients.

\section{Mechanisms of decreased ADAMTS13 activity in trauma patients}

Secondary deficiency of ADAMTS13 are reported due to a reduced production in the liver [24], consumption through ongoing cleavage of ULvWF [2, 25], inhibition by inflammatory cytokines [26], cleavage by neutrophil elastase [27], plasmin, or thrombin [27, 28]. The present results showed that the decreased ADAMTS13 activity in the very early phase of trauma was correlated with the changes in coagulofibrinolytic markers and serum levels of IL-6, so that the possible mechanisms in the previous reports describing as coagulopathy and systemic inflammation could be supported by the present results. As shown in the Fig. 2, another major finding of this study is that ADAMTS13 activities showed positive correlations with AT activity and serum Alb levels even on day 0 . AT and Alb decrease in the acute phase of the critical conditions such as sepsis [29-31] or trauma [32] possibly through vascular leakage from its augmented permeability $[33,34]$. So, also in trauma, there is a possibility that vascular leakage might be involved in the changes in AT and Alb levels with ADAMTS13 activities.

On the other hand, we showed also in the Fig. 2 that the correlations between platelet counts and D-dimer levels with ADAMTS13 activities were significant, so, these correlations might imply thrombus formation due to trauma induced hypercoagulation. However, all these correlations depicted in the Fig. 2 were not so robust, which suggest that some other factors also might affect ADAMTS13 activity in the very early phase of trauma. So, we need to define such points in the future.

\section{Clinical significance of decreased ADAMTS13 activity in trauma patients}

In our current adult trauma study, moderately decreased ADAMTS13 activities $(<50 \%)$ on day 0 were significantly associated with platelet depletion, development of DIC and a need for transfusion of FFP. Furthermore, the decreased ADAMTS13 activities on day 0 were improved over time, which was most likely due to transfusion of FFP for the treatment of coagulopathy after trauma.

Ono et al. reported that in septic DIC patients, a severe reduction in ADAMTS13 activity developed and suggested that sepsis may have a similar condition of severe ADAMTS13 deficiency for developing TMA. They also implied a potential supportive therapy of ADAM TS13 supplementation in sepsis [20]. Trauma also activates coagulofibrinolytic responses to occasionally provoke trauma-induced coagulopathy (TIC), which could eventually cause DIC. TIC with systemic inflammation and endothelial cell injury may cause ADAMTS13 decrease [10], which might be a risk of further platelet consumption and thrombus formation [35]. Transfusion of FFP could supply not only coagulation factors but also ADAMTS13, which might result in suppressing excessive platelet aggregation and exhaustion, or stabilizing endothelial conditions, possibly by increasing ADAM TS13 levels [36].

The levels of decrease in ADAMTS13 seem to play important roles in the disease severity and thrombotic disorders. However, cut-off values of ADAMTS13 activity that could predict the prognosis and the development of thrombotic disorders vary across different critical conditions. In the current study, we showed the actual influence of decreased ADAMTS13 activity on coagulation activity or thrombus formation. So, in the future, we need to clarify the range of ADAMTS13 activity differentiating the pathophysiological severity, which could contribute to determine treatment interventions. 


\section{Limitations of this study}

Several limitations of the present study should be addressed. First, the sample size of this study was small, so even though we obtained the present results by the appropriate statistical methods, we need larger-scale studies to clarify our hypotheses. Second, we did not assess the levels of vWF and its multimer which directly affects coagulation associated with ADAMTS13 in this study, so we need to examine them to clarify the pathogenesis of the association between ADAMTS13 and traumainduced coagulopathy. Third, we included cases with mild trauma severity (i.e., those who survived for longer than 7 days), but one of the aims of this study was to examine the serial time course changes in ADAMTS13 activity in adult trauma patients, which have not yet been examined. We therefore might need to include such patients with mild severity. Even after the inclusion of such patients, we detected the clear coagulofibrinolytic responses and ADAMTS13 reductions. However, further studies, including more severe cases, might be required to determine the hemostatic status under different conditions. Fourth, we did not assess a sufficient range of issues regarding the site of trauma, since many patients included in this study suffered from blunt trauma to multiple organs. Therefore, there is the possibility that coagulofibrinolytic responses differ depending on the injured organs especially if the brain is involved. Accordingly, a future study considering the injured sites of trauma is needed to clarify this point.

\section{Conclusions}

ADAMTS13 activity decreased even in the early phase of trauma, which was correlated with inflammatory and coagulofibrinolytic responses. Furthermore, the decreased ADAMTS13 activity was correlated with the development of DIC and the requirement of transfusion of FFP. Severe trauma patients with ADAMTS13 activity reductions might experience complications from coagulopathy.

\footnotetext{
Abbreviations

ADAMTS13: The 13th member of a disintegrin-like and metalloprotease with thrombospondin type 1 motif; AT: Antithrombin; TAT: Thrombinantithrombin complex; Alb: Albumin; sTM: Soluble thrombomodulin; tPA: Tissue plasminogen activator; PC: Protein C; tPAl-1: Total plasminogen activator inhibitor-1; PT: Prothrombin time; APTT: Activated partial thromboplastin time; Fbg: Fibrinogen; FDP: Fibrin/fibrinogen degradation product; PIC: Plasmin- $a_{2}$-plasmin inhibitor complex; $a_{2} P I$ : $a_{2}$-plasmin inhibitor; PLG: Plasminogen; TIC: Trauma-induced coagulopathy; DIC: Disseminated intravascular coagulation; ISS: Injury Severity Score; JAAM: The Japanese Association for Acute Medicine; IVR: Interventional radiology; ORIF: Open reduction and internal fixation
}

\section{Acknowledgements}

The authors would like to thank the nursing staff of the Intensive Care Unit 2 at Ehime University Hospital for their assistance.

\section{Authors' contributions}

HM conceived and designed the study. HM, JT, KU, SK, MO, SA, and YN prepared the data for analysis. HM conducted the data analysis. JT, UK, NS and MA assisted with the interpretation of the results and supervised the study. HM and MA drafted the article. All authors read and approved the manuscript. HM and MA take responsibility for the paper as a whole.

\section{Funding}

No funding was received for this study.

\section{Availability of data and materials}

The datasets for the current study are available from the corresponding author upon reasonable request.

\section{Declarations}

Ethics approval and consent to participate

This study was approved by the Institutional Local Ethics Committee for Clinical Studies at Ehime University Graduate School of Medicine. Informed consent was obtained from all patients or next of kin in accordance with the Declaration of Helsinki.

\section{Consent for publication}

Written informed consent was obtained from all patients or next of kin for publication of their individual details in this manuscript. The consent form is held by the authors and is available for review by the Editor-in-Chief.

\section{Competing interests}

The authors declare that they have no competing interests.

Received: 7 June 2020 Accepted: 3 March 2021

Published online: 12 March 2021

\section{References}

1. Sadler JE. Von Willebrand factor, ADAMTS13, and thrombotic thrombocytopenic purpura. Blood. 2008;112(1):11-8.

2. Dong JF, Moake JL, Nolasco L, Bernardo A, Arceneaux W, Shrimpton CN, Schade AJ, McIntire LV, Fujikawa K, López JA. ADAMTS-13 rapidly cleaves newly secreted ultralarge von Willebrand factor multimers on the endothelial surface under flowing conditions. Blood. 2002;100(12):4033-9.

3. Sadler JE. Pathophysiology of thrombotic thrombocytopenic purpura. Blood. 2017;130(10):1181-8

4. Moake JL. Thrombotic microangiopathies. N Engl J Med. 2002;347(8):589600.

5. South K, Lane DA. ADAMTS-13 and von Willebrand factor: a dynamic duo. J Thromb Haemost. 2018;16(1):6-18.

6. Feng Y, Li X, Xiao J, Li W, Liu J, Zeng X, Chen X, Chen S. ADAMTS13: more than a regulator of thrombosis. Int J Hematol. 2016;104(5):534-9.

7. Saha M, McDaniel JK, Zheng XL. Thrombotic thrombocytopenic purpura: pathogenesis, diagnosis and potential novel therapeutics. J Thromb Haemost. 2017;15(10):1889-900.

8. Masias C, Cataland SR. The role of ADAMTS13 testing in the diagnosis and management of thrombotic microangiopathies and thrombosis. Blood. 2018;132(9):903-10.

9. Wada H, Matsumoto T, Suzuki K, Imai H, Katayama N, Iba T, Matsumoto M. Differences and similarities between disseminated intravascular coagulation and thrombotic microangiopathy. Thromb J. 2018;16:14.

10. Russell RT, McDaniel JK, Cao W, Shroyer M, Wagener BM, Zheng XL, Pittet JF. Low plasma ADAMTS13 activity is associated with coagulopathy, endothelial cell damage and mortality after severe paediatric trauma. Thromb Haemost. 2018;118(4):676-87.

11. Moore HB, Gando S, Iba T, Kim PY, Yeh CH, Brohi K, Hunt BJ, Levy JH, Draxler DF, Stanworth S, Görlinger K, Neal MD, Schreiber MA, Barrett CD, Medcalf RL, Moore EE, Mutch NJ, Thachil J, Urano T, Thomas S, Scărlătescu E, Walsh M, Subcommittees on Fibrinolysis, Disseminated Intravascular Coagulation, and Perioperative and Critical Care Thrombosis and Hemostasis. Defining trauma-induced coagulopathy with respect to future implications for patient management: Communication from the SSC of the ISTH. J Thromb Haemost. 2020;18(3):740-7.

12. Gando S, Wada H, Kim HK, Kurosawa S, Nielsen JD, Thachil J, Toh CH, Scientific and Standardization Committee on DIC of the ISTH. Comparison 
of disseminated intravascular coagulation in trauma with coagulopathy of trauma/acute coagulopathy of trauma-shock. J Thromb Haemost. 2012; 10(12):2593-5.

13. Bone RC, Balk RA, Cerra FB, Dellinger RP, Fein AM, Knaus WA, Schein RM, Sibbald WJ. Definitions for sepsis and organ failure and guidelines for the use of innovative therapies in sepsis. The ACCP/SCCM Consensus Conference Committee American College of Chest Physicians/Society of Critical Care Medicine. Chest. 1992:101(6):1644-55.

14. Gando S, Saitoh D, Ogura H, Mayumi T, Koseki K, Ikeda T, Ishikura H, Iba T, Ueyama M, Eguchi Y, Ohtomo Y, Okamoto K, Kushimoto S, Endo S, Shimazaki S, Japanese Association for Acute Medicine Disseminated Intravascular Coagulation (JAAM DIC) Study Group. Natural history of disseminated intravascular coagulation diagnosed based on the newly established diagnostic criteria for critically ill patients: results of a multicenter, prospective survey. Crit Care Med. 2008:36(1):145-50.

15. Kato S, Matsumoto M, Matsuyama T, Isonishi A, Hiura H, Fujimura Y. Novel monoclonal antibody-based enzyme immunoassay for determining plasma levels of ADAMTS13 activity. Transfusion. 2006;46(8):1444-52.

16. Fujimura Y, Matsumoto M. Registry of 919 patients with thrombotic microangiopathies across Japan: database of Nara Medical University during 1998-2008. Intern Med. 2010:49(1):7-15.

17. Masias C, Vasu S, Cataland SR. None of the above: thrombotic microangiopathy beyond TTP and HUS. Blood. 2017;129(21):2857-63.

18. Farkas P, Csuka D, Mikes B, Sinkovits G, Réti M, Németh E, Rácz K, Madách K, Gergely M, Demeter J, Prohászka Z. Complement activation, inflammation and relative ADAMTS13 deficiency in secondary thrombotic microangiopathies. Immunobiology. 2017;222(2):119-27.

19. Martin K, Borgel D, Lerolle N, Feys HB, Trinquart L, Vanhoorelbeke K, Deckmyn H, Legendre P, Diehl JL, Baruch D. Decreased ADAMTS-13 (A disintegrin-like and metalloprotease with thrombospondin type 1 repeats) is associated with a poor prognosis in sepsis-induced organ failure. Crit Care Med. 2007;35(10):2375-82.

20. Ono T, Mimuro J, Madoiwa S, Soejima K, Kashiwakura Y, Ishiwata A, Takano $\mathrm{K}$, Ohmori T, Sakata Y. Severe secondary deficiency of von Willebrand factorcleaving protease (ADAMTS13) in patients with sepsis-induced disseminated intravascular coagulation: its correlation with development of renal failure. Blood. 2006;107(2):528-34.

21. Levi M, Scully M, Singer M. The role of ADAMTS-13 in the coagulopathy of sepsis. J Thromb Haemost. 2018;16(4):646-51.

22. Aibar J, Castro P, Espinosa G, Fernández S, Hernández C, Rinaudo M, Butjosa M, Tàssies D, Reverter JC, Nicolás JM. ADAMTS-13 in critically ill patients with septic syndromes and noninfectious systemic inflammatory response syndrome. Shock. 2015;43(6):556-62.

23. Lin JJ, Chan OW, Hsiao HJ, Wang Y, Hsia SH, Chiu CH. Decreased ADAMTS 13 activity is associated with disease severity and outcome in pediatric severe sepsis. Medicine (Baltimore). 2016;95(16):e3374.

24. Uemura M, Tatsumi K, Matsumoto M, Fujimoto M, Matsuyama T, Ishikawa M, Iwamoto TA, Mori T, Wanaka A, Fukui H, Fujimura Y. Localization of ADAM TS13 to the stellate cells of human liver. Blood. 2005:106(3):922-4.

25. Dong JF, Moake JL, Bernardo A, Fujikawa K, Ball C, Nolasco L, López JA, Cruz MA. ADAMTS-13 metalloprotease interacts with the endothelial cell-derived ultra-large von Willebrand factor. J Biol Chem. 2003;278(32):29633-9.

26. Bernardo A, Ball C, Nolasco L, Moake JF, Dong JF. Effects of inflammatory cytokines on the release and cleavage of the endothelial cell-derived ultralarge von Willebrand factor multimers under flow. Blood. 2004;104(1): 100-6.

27. Hiura $\mathrm{H}$, Matsui $\mathrm{T}$, Matsumoto $\mathrm{M}$, Hori $\mathrm{Y}$, Isonishi A, Kato S, Iwamoto T, Mori T, Fujimura Y. Proteolytic fragmentation and sugar chains of plasma ADAM TS13 purified by a conformation-dependent monoclonal antibody. J Biochem. 2010;148(4):403-11.

28. Crawley JT, Lam JK, Rance JB, Mollica LR, O'Donnell JS, Lane DA. Proteolytic inactivation of ADAMTS13 by thrombin and plasmin. Blood. 2005;105(3): 1085-93.

29. Aibiki M, Fukuoka N, Umakoshi K, Ohtsubo S, Kikuchi S. Serum albumin levels anticipate antithrombin III activities before and after antithrombin III agent in critical patients with disseminated intravascular coagulation. Shock. 2007;27(2):139-44.

30. Asakura H, Ontachi $Y$, Mizutani T, Kato M, Ito T, Saito M, Morishita E, Yamazaki M, Aoshima K, Takami A, Yoshida T, Suga Y, Miyamoto K, Nakao S. Decreased plasma activity of antithrombin or protein $\mathrm{C}$ is not due to consumption coagulopathy in septic patients with disseminated intravascular coagulation. Eur J Haematol. 2001;67(3):170-5.

31. Kobayashi A, Matsuda Y, Mitani M, Makino Y, Ohta H. Assessment of the usefulness of antithrombin-III in the management of disseminated intravascular coagulation in obstetrically ill patients. Clin Appl Thromb Hemost. 2010;16(6):688-93.

32. Matsumoto H, Takeba J, Umakoshi K, Kikuchi S, Ohshita M, Annen S, Moriyama N, Nakabayashi Y, Sato N, Aibiki M. Decreased antithrombin activity in the early phase of trauma is strongly associated with extravascular leakage, but not with antithrombin consumption: a prospective observational study. Thromb J. 2018;16:17.

33. Margarson MP, Soni N. Serum albumin: touchstone or totem? Anaesthesia. 1998;53(8):789-803.

34. Boldt J. Use of albumin: an update. Br J Anaesth. 2010;104(3):276-84.

35. Chauhan AK, Kisucka J, Brill A, Walsh MT, Scheiflinger F, Wagner DD. ADAM TS13: a new link between thrombosis and inflammation. J Exp Med. 2008; 205(9):2065-74.

36. Straat M, Müller MC, Meijers JC, Arbous MS, Spoelstra-de Man AM, Beurskens CJ, Vroom MB, Juffermans NP. Effect of transfusion of fresh frozen plasma on parameters of endothelial condition and inflammatory status in nonbleeding critically ill patients: a prospective substudy of a randomized trial. Crit Care. 2015:19:163.

\section{Publisher's Note}

Springer Nature remains neutral with regard to jurisdictional claims in published maps and institutional affiliations.
Ready to submit your research? Choose BMC and benefit from:

- fast, convenient online submission

- thorough peer review by experienced researchers in your field

- rapid publication on acceptance

- support for research data, including large and complex data types

- gold Open Access which fosters wider collaboration and increased citations

- maximum visibility for your research: over $100 \mathrm{M}$ website views per year

At BMC, research is always in progress.

Learn more biomedcentral.com/submissions 